\title{
Convalescent Plasma-A Light at the End of the Tunnel: A Systematic Review and Meta-analysis of Randomized Controlled Trials
}

\author{
Soumya Sarkar ${ }^{1} \odot$, Puneet Khanna ${ }^{2}$, Akhil K Singh $^{3} \odot$
}

\begin{abstract}
In the absence of a definitive therapy during this ongoing unprecedented crisis, coronavirus disease-2019 (COVID-19) pandemic, convalescent plasma transfusion (CPT) has shown some promising results. This review summarizes the existing evidence of the efficacy of CPT in COVID-19 patients based upon scientific publications to date.

We have included only the randomized controlled trials (RCTs) through an extensive screening of electronic databases up to July $31,2021$. In 19 RCTs, with a total of 16,476 COVID-19 patients we found low-quality evidence of significant reduction in mortality (odds ratio (OR) $=0.80$; $95 \%$ confidence interval $\left.(\mathrm{Cl}): 0.66-0.96, \mathrm{I}^{2}=40 \%\right)$, better clinical outcome when applied $<7$ days $\left(\mathrm{OR}=2.13,95 \% \mathrm{Cl} 1.28-3.53, \mathrm{I}^{2}=0 \%\right)$, and improved viral clearance $\left(\mathrm{OR}=2.6,95 \% \mathrm{Cl}: 1.3-5.45, \mathrm{I}^{2}=74 \%\right)$. Meta-regression analysis found that as a covariate, intubation on admission $(p=0.007)$ had a significant impact. However, there was any significant reduction neither in duration for clinical improvement $(M D=-0.79$, $\left.95 \% \mathrm{Cl}:-2.76-1.18, \mathrm{I}^{2}=98 \%\right)$, nor in total period of hospital stay (MD $\left.=0.02,95 \% \mathrm{Cl}:-0.75-0.78, \mathrm{I}^{2}=81 \%\right)$.

Early application of CPT is still relevant in reducing morbidity and mortality in critically ill patients and is too early to write it off as a potential therapeutic modality for COVID-19 patients.

Keywords: Convalescent plasma, Coronavirus disease 2019, Meta-analysis, Randomized controlled trial, SARS-CoV-2.

Indian Journal of Critical Care Medicine (2021): 10.5005/jp-journals-10071-24023
\end{abstract}

\section{INTRODUCTION}

In the absence of definitive therapy for the novel coronavirus disease-2019 (COVID-19), caused by severe acute respiratory syndrome coronavirus-2 (SARS-CoV-2), the US Food and Drug Administration (FDA) approved the use of convalescent plasma therapy (CPT) in COVID-19 patients under the emergency investigational new drug category. ${ }^{1}$

Traditionally during epidemics, the CPT has been tried in patients whose critical condition is refractory to supportive care. ${ }^{2}$ The plasma is procured from a recently recovered person from a viral illness, which is supposed to have the maximum levels of polyclonal antibodies directed against the virus. ${ }^{3}$

The passive immune therapy has evolved from convalescent whole blood, convalescent plasma, pooled human immunoglobulin, and polyclonal or monoclonal antibodies, to the current practice of plasma collected by apheresis. ${ }^{4}$ The practice of using blood products from recovered patients as a therapeutic agent was way back in the late 1800s. CPT has been effectively used since the Spanish influenza pandemic in 1915-1917, ${ }^{5}$ severe acute respiratory syndrome (SARS) in $2003,{ }^{6}$ influenza $A(H 1 N 1)$ in $2009{ }^{7}$ avian influenza A (H5N1), ${ }^{8}$ and even in viral hemorrhagic fever-like Ebola. ${ }^{3}$

The CPT seems to be a promising option, with some early promising results on the improvement of clinical symptoms and reduction in mortality. However, the clinical evidence in this regard is still inconclusive and contradictory. Thus, the purpose of this review is to analyze the current evidence of the efficacy and safety

\begin{abstract}
${ }^{1-3}$ Department of Anesthesia, Pain Medicine and Critical Care, AllMS, Delhi, India

Corresponding Author: Puneet Khanna, Department of Anesthesia, Pain Medicine and Critical Care, AllMS, Delhi, India, Phone: +919873106516, e-mail: k.punit@yahoo.com

How to cite this article: Sarkar S, Khanna P, Singh AK. Convalescent Plasma-A Light at the End of the Tunnel: A Systematic Review and Meta-analysis of Randomized Controlled Trials. Indian J Crit Care Med 2021;25(11):1292-1300.
\end{abstract}

Source of support: Nil

Conflict of interest: None

of convalescent plasma therapy in COVID-19 patients. We have followed the Preferred Reporting Items for Systematic Reviews and Meta-Analyses (PRISMA-P) guidelines.

\section{Methods}

\section{Search Strategy}

The authors PK and SS independently searched the major electronic databases (PubMed, MEDLINE, and Embase), Google Scholar (https://scholar.google.com), and preprint platforms medRxiv (https://www.medrxiv.org) from January 1, 2020, to July 31, 2021, with the following keywords: "COVID-19" OR "SARS-CoV-2" AND "plasma" OR "convalescent plasma" AND "Randomized Controlled trials" OR "RCT."

(0) The Author(s). 2021 Open Access This article is distributed under the terms of the Creative Commons Attribution 4.0 International License (https://creativecommons. org/licenses/by-nc/4.0/), which permits unrestricted use, distribution, and non-commercial reproduction in any medium, provided you give appropriate credit to the original author(s) and the source, provide a link to the Creative Commons license, and indicate if changes were made. The Creative Commons Public Domain Dedication waiver (http://creativecommons.org/publicdomain/zero/1.0/) applies to the data made available in this article, unless otherwise stated. 


\section{Inclusion and Exclusion Criteria}

The RCTs over CPT in COVID-19 patients published in the English language were included. Our primary outcome of interest was mortality and viral clearance was the secondary outcome (PRISMA flow diagram).

Controlled clinical trials, comparative cohort studies, and casecontrol studies-cross-sectional studies with a control group on convalescent plasma therapy for COVID-19 patients were excluded.

\section{Study Selection}

Initially, SS and PK screened every available abstract separately after the removal of the duplications for excluding the irrelevant articles. After that, the full texts of the potential studies were examined. Disagreements were consulted with AKS.

\section{Data Extraction}

SS and PK extracted the data of the first author, year of publication, type of study, place, sample size, details of the intervention and control groups, mortality, clinical improvement, and viral clearance by using a preconceived data extraction sheet individually.

\section{Risk of Bias Assessment}

PK and SS assessed the potential bias in every selected study individually with the Risk of Bias (RoB) 2.0 tool after resolving the difference of opinion with the consultation of AKS.

\section{Quality of the Evidence}

PK and AKS evaluated the quality of evidence independently by the Grading of Recommendations Assessment, Development, and Evaluation (GRADE) tool.

Flowchart 1: PRISMA-2009 flow diagram

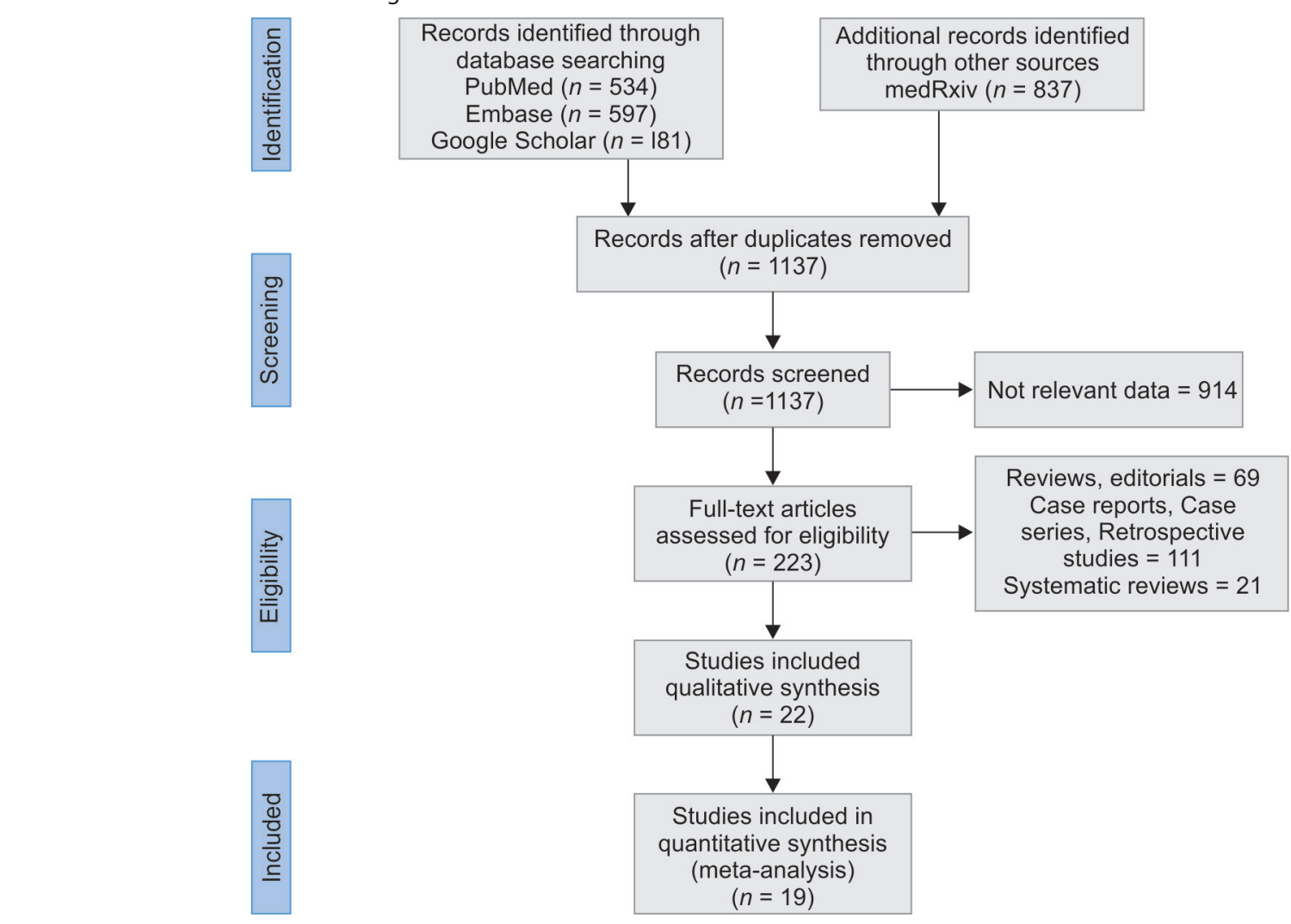

\section{Data Synthesis}

We used the Review Manager version 5.4 for conducting this metaanalysis along with subgroup analyses based upon severity and administration time of CPT, and the comprehensive meta-analysis version 3 for conducting meta-regression analysis. We calculated the odds ratio (OR) with $95 \%$ confidence interval $(\mathrm{Cl})$ according to the Cochrane Handbook for Systematic Reviews of Interventions. Statistical heterogeneity was assessed with the $\mathrm{I}^{2}>50 \%$, indicating substantial heterogeneity. A funnel plot was used to assess publication bias.

\section{Results}

\section{Basic Characteristics}

A total of 19 studies out of 1,337 identified publications were included after satisfying the inclusion criteria and 9 of them were preprints (Flowchart 1; Table 1).

\section{Meta-analysis}

Mortality

A significant reduction in mortality among COVID-19 patients with CPT (OR $\left.=0.80 ; 95 \% \mathrm{Cl}: 0.66-0.96, \mathrm{I}^{2}=40 \%\right)$ was found in $19 \mathrm{RCTs}$ ( $n=1,409$ patients) (Fig. 1).

In subgroup analysis, though the impact of CPT on mortality among critically ill patients (OR $\left.=0.68 ; 95 \% \mathrm{Cl}: 0.52-0.88, \mathrm{I}^{2}=59 \%\right)$ was significant, the patients with mild $(\mathrm{OR}=1.00 ; 95 \% \mathrm{Cl}: 0.75-1.35$, $\left.\mathrm{I}^{2}=0 \%\right)$ or moderate illness (OR $\left.=0.70 ; 95 \% \mathrm{Cl}: 0.27-1.83, \mathrm{I}^{2}=46 \%\right)$ showed no additional benefit. 


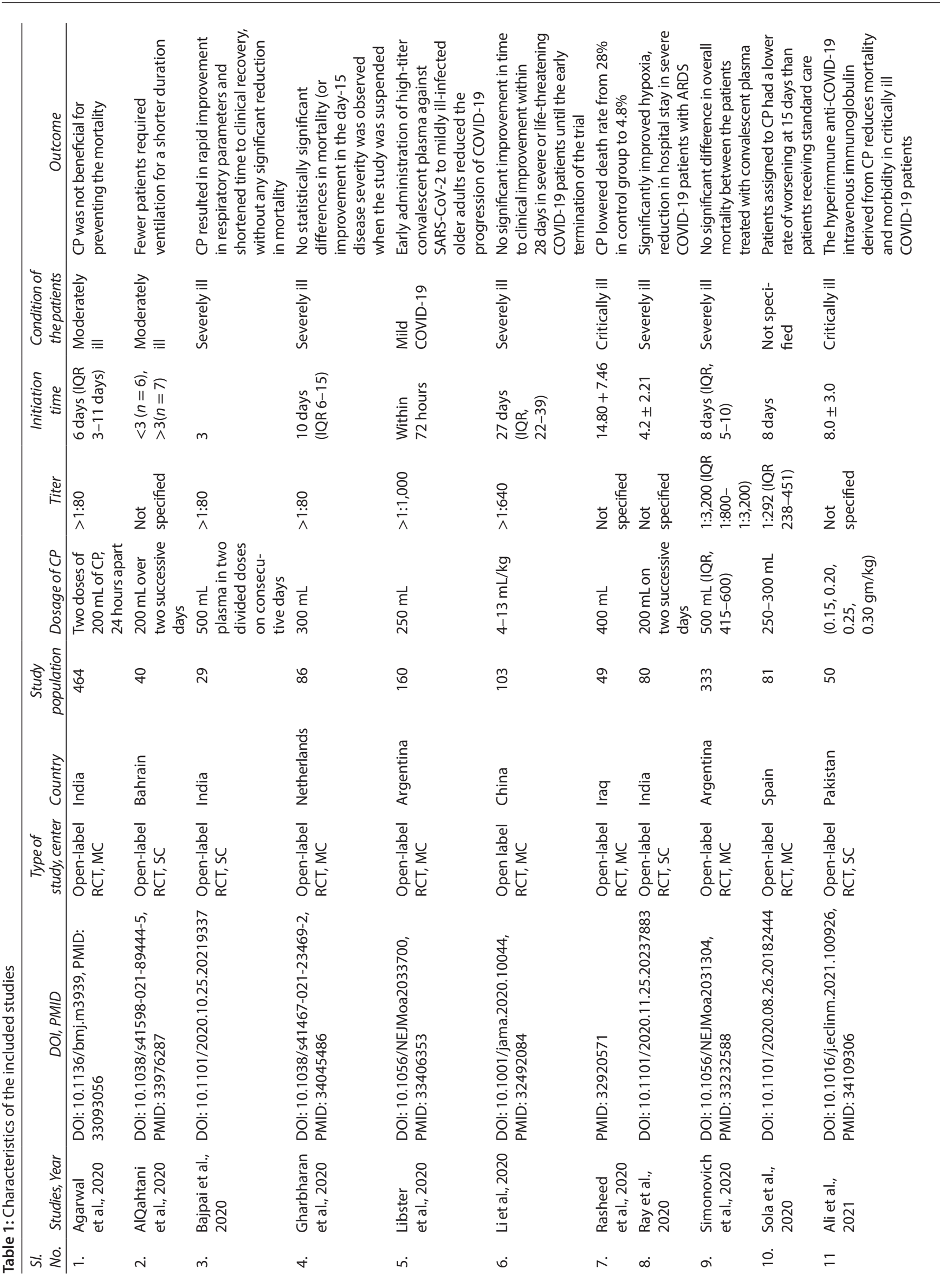



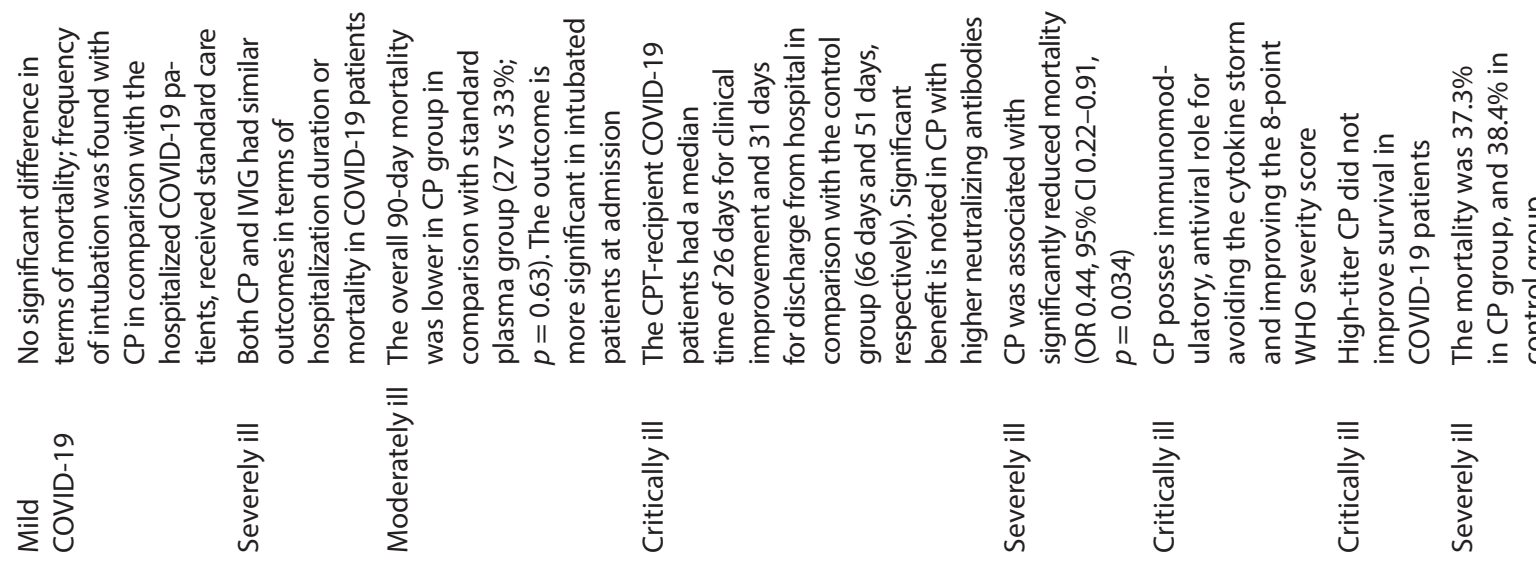

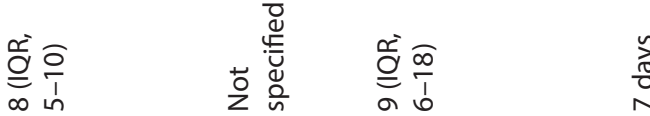

$\frac{n}{0}$

$\stackrel{\circ}{\stackrel{0}{\check{r}}}$

$\stackrel{1}{\varepsilon}$

เ్

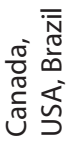

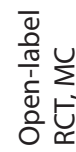

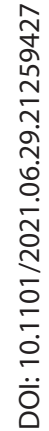

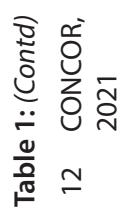

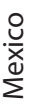

ฐ

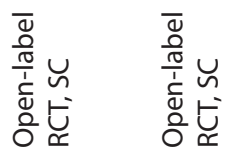

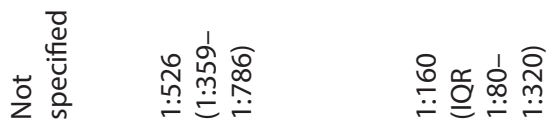

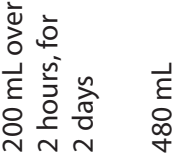

$\underline{6}$

ホ

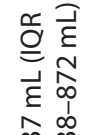

$\hat{m}_{\infty}^{\infty} \stackrel{\infty}{\wedge}$

$\stackrel{\leftrightarrow}{\circ}$

$\underset{\substack{\mathbb{0} \\ \frac{\mathrm{E}}{d}}}{\mathrm{v}}$

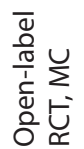

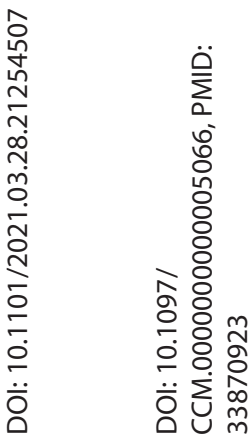

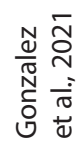

$m$

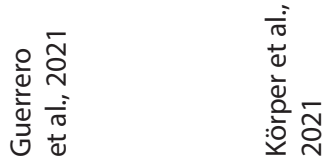

$\pm$

느

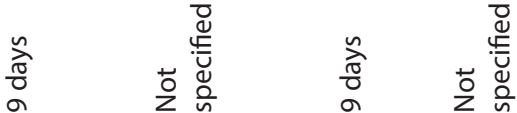

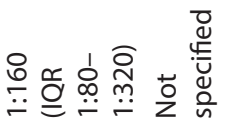

$\begin{array}{ll}\circ & \circ \\ \frac{0}{\wedge} & \frac{0}{\wedge}\end{array}$

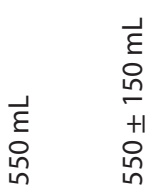

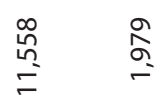

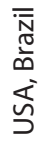

$\stackrel{ }{\stackrel{ }{ }}$

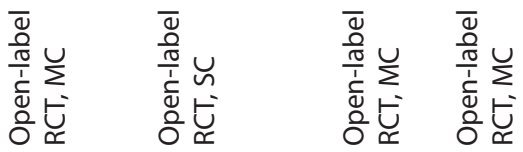

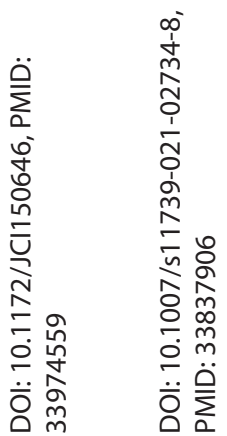

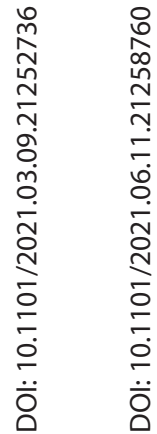
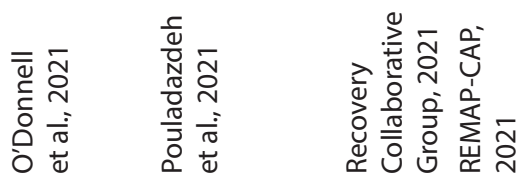

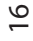

$\infty \quad$

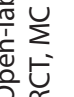

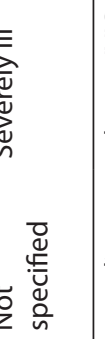

$\frac{0}{\circ 1}$

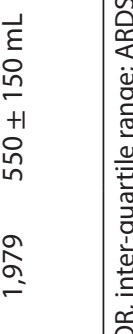
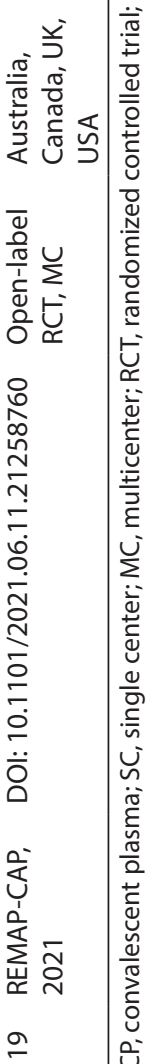


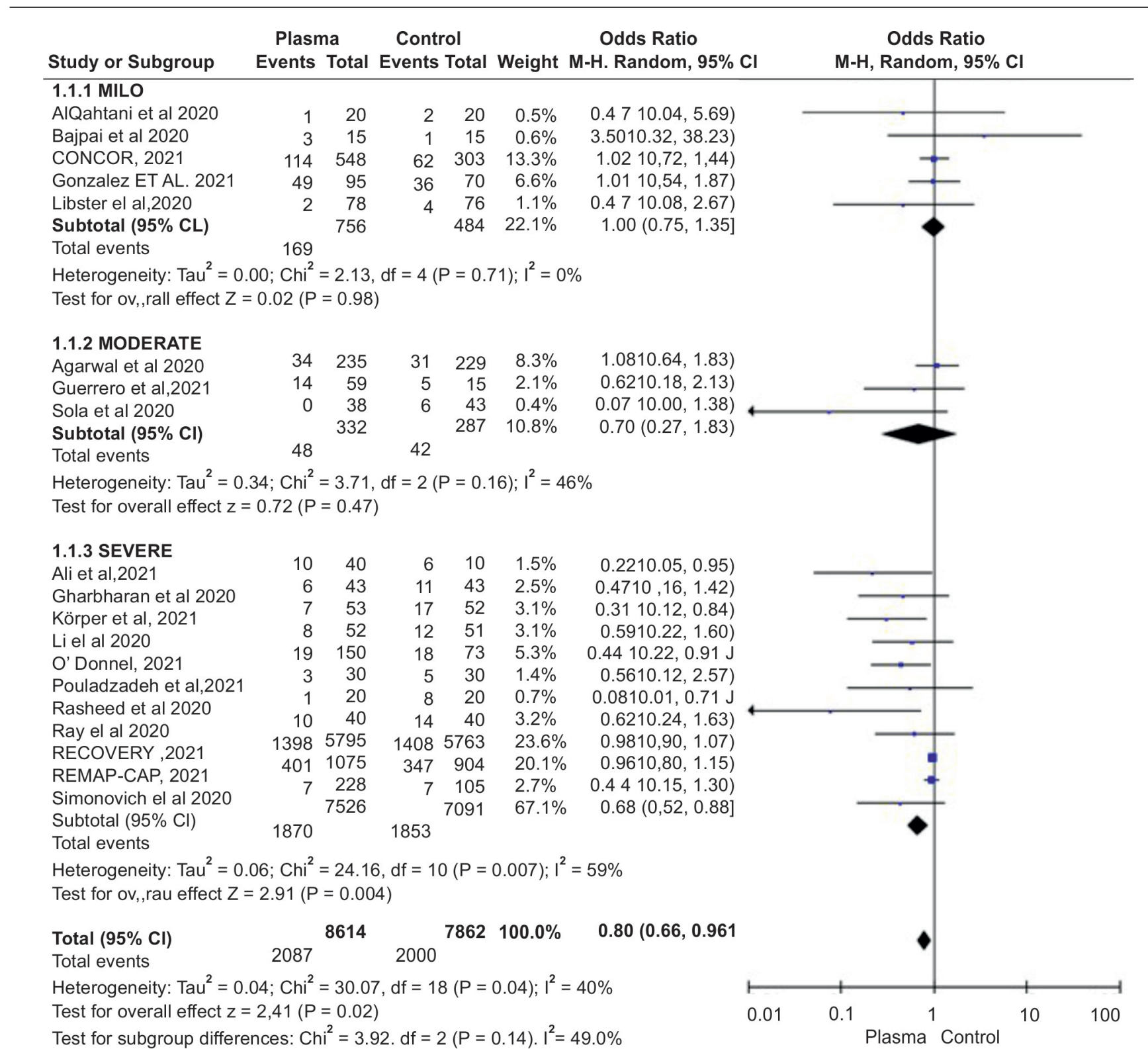

Fig. 1: The efficacy of convalescent plasma therapy on mortality in COVID-19 patients

\section{Clinical Improvement}

Thirteen RCTs with 13,320 patients indicated that no statistically significant clinical improvement $\left(\mathrm{OR}=1.27,95 \% \mathrm{Cl} 1-1.61, \mathrm{I}^{2}=45 \%\right)$ in CPT-recipient COVID-19 patients in comparison with patients who received standard care (Fig. 2A).

However, in a subgroup analysis of five studies $(n=369)$ where CPT was applied $<7$ days of symptoms, there are significantly higher odds for clinical improvement $\left(\mathrm{OR}=2.13,95 \% \mathrm{Cl} 1.28-3.53, \mathrm{I}^{2}=0 \%\right)$.

\section{Viral Clearance}

Viral clearance was assessed in four RCTs $(n=631)$. Significant clearance of viral shedding $\left(\mathrm{OR}=2.66,95 \% \mathrm{Cl} 1.3-5.45, \mathrm{I}^{2}=74 \%\right)$ was found in CPT-recipient COVID-19 patients. However, the result is highly heterogeneous (Fig. 2B).

\section{Period for Clinical Improvement and Hospital Stay}

The CPT recipients showed a significant reduction neither in duration for clinical improvement $(\mathrm{MD}=-0.79,95 \% \mathrm{Cl}$ : $-2.76-1.18$,
$1^{2}=98 \% ; n=354$ ) (Fig. 2C) nor in overall period for hospital stay $\left(\mathrm{MD}=0.02,95 \% \mathrm{Cl}:-0.75-0.78, \mathrm{I}^{2}=81 \% ; n=1,208\right)$ (Fig. 2D).

\section{Meta-regression}

Meta-regression analysis found that the association between CPT and mortality in COVID-19 patients was influenced only by intubation status on admission ( $p=0.007$ ) (Fig. 2E), but not by volume $(p=0.676)$, titer $(p=0.464)$, concomitant use of steroid ( $p=0.650)$, tocilizumab $(p=0.864)$, remdesivir $(p=0.524)$, presence of preexisting lung disease $(p=0.236)$, and diabetes $(p=0.151)$.

Publication bias for the studies on COVID-19 mortality was assessed. The funnel plot indicates that a publication bias is likely as few smaller studies were associated with large effects (Supplemental Fig. 1).

Supplemental Figs 1 A and B: (A) Funnel plot of the included studies for assessment of publication bias; (B) ROB-2 assessment for the included randomized controlled trials 


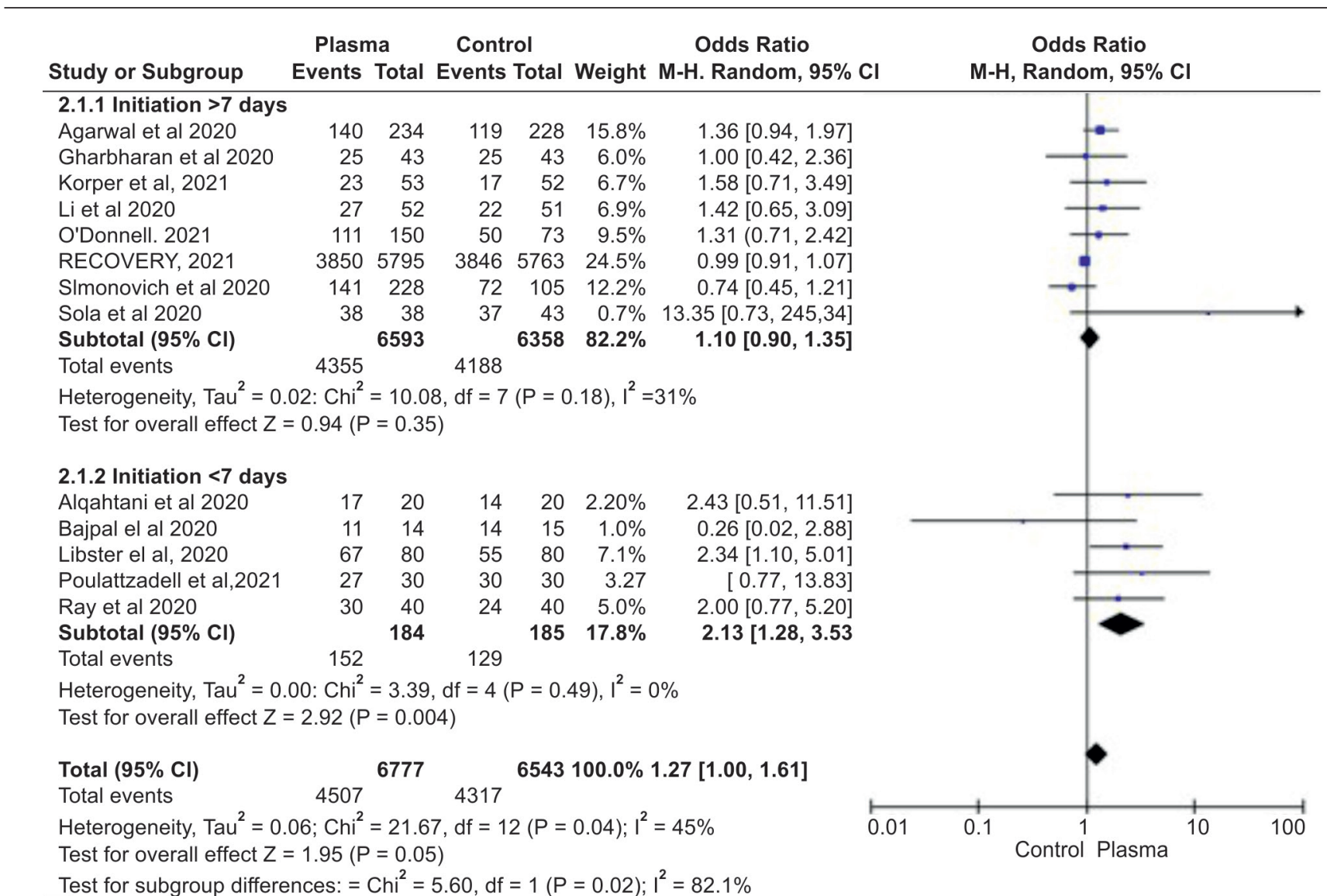

A

Plasma Control Odds Ratio

Study or Subgroup Events Total Events Total Weight M-H. Random, 95\% Cl M-H, Random, 95\% Cl

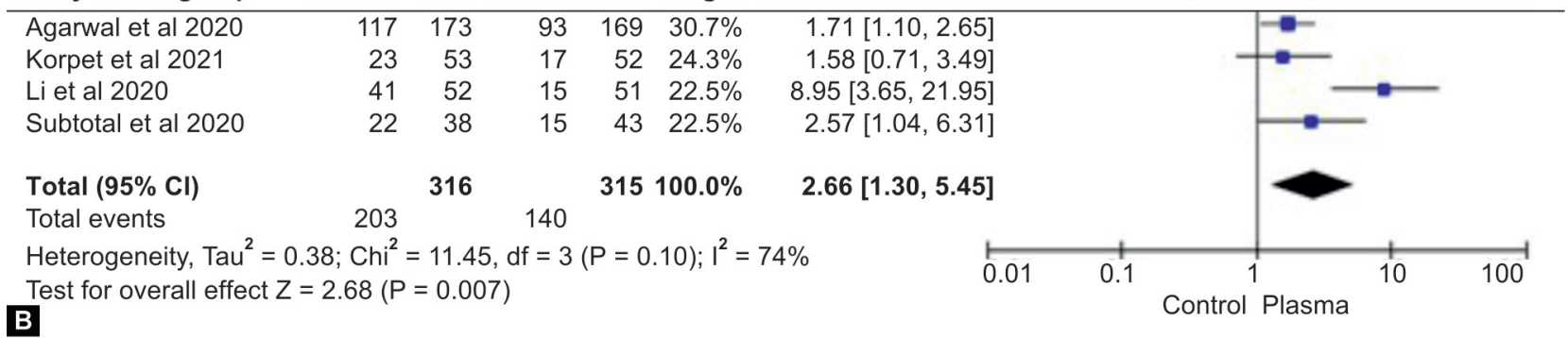

Figs 2A and B: (A) The impact of convalescent plasma therapy on clinical improvement in COVID-19 patients; (B) The effect of convalescent plasma therapy on viral clearance in COVID-19 patients

\section{Discussion}

We have identified low-quality evidence with variability that the lower odds of mortality along with better clearance of viral shedding in COVID-19 patients who received the convalescent plasma therapy. (Table 2)

Similarly, a recent systematic review also found a significant reduction of mortality (risk ratio $(\mathrm{RR})=0.57,95 \% \mathrm{Cl} 0.44-0.74$, $\left.\mathrm{I}^{2}=0 \%\right)$ in nine controlled studies with severely and critically ill COVID-19 patients. ${ }^{9}$

Previously, Sarkar et al. ${ }^{10}$ also found low-quality evidence of reduced mortality (OR 0.44; 95\% $\mathrm{Cl} 0.25-0.77$ ), and better clearance of viral shedding (OR, 11.29; 95\% Cl, 4.9-25.9) among CPT-recipient COVID-19 patients, in two RCTs and five matched cohort studies.
Another recent systematic review also reported a significant decrease in viral loads and improvement in clinical symptoms within 3-26 days post-CPT for the management of COVID-19.11

However, a living systematic review reported very low-quality evidence of no beneficial effect of CPT in reducing all-cause mortality at hospital discharge [RR $0.89,95 \% \mathrm{Cl} 0.61-1.31$ ] in one RCT and three controlled non-randomized studies of interventions, respectively. ${ }^{12}$

Another meta-analysis on efficacy and safety of convalescent plasma for severe COVID-19 based on evidence in other severe respiratory viral infections also found very low-quality noninformative results about complete recovery (OR 1.04, 95\% Cl $0.69-1.64$ ), the period of hospital stays (mean difference-1.62, $95 \%$ 


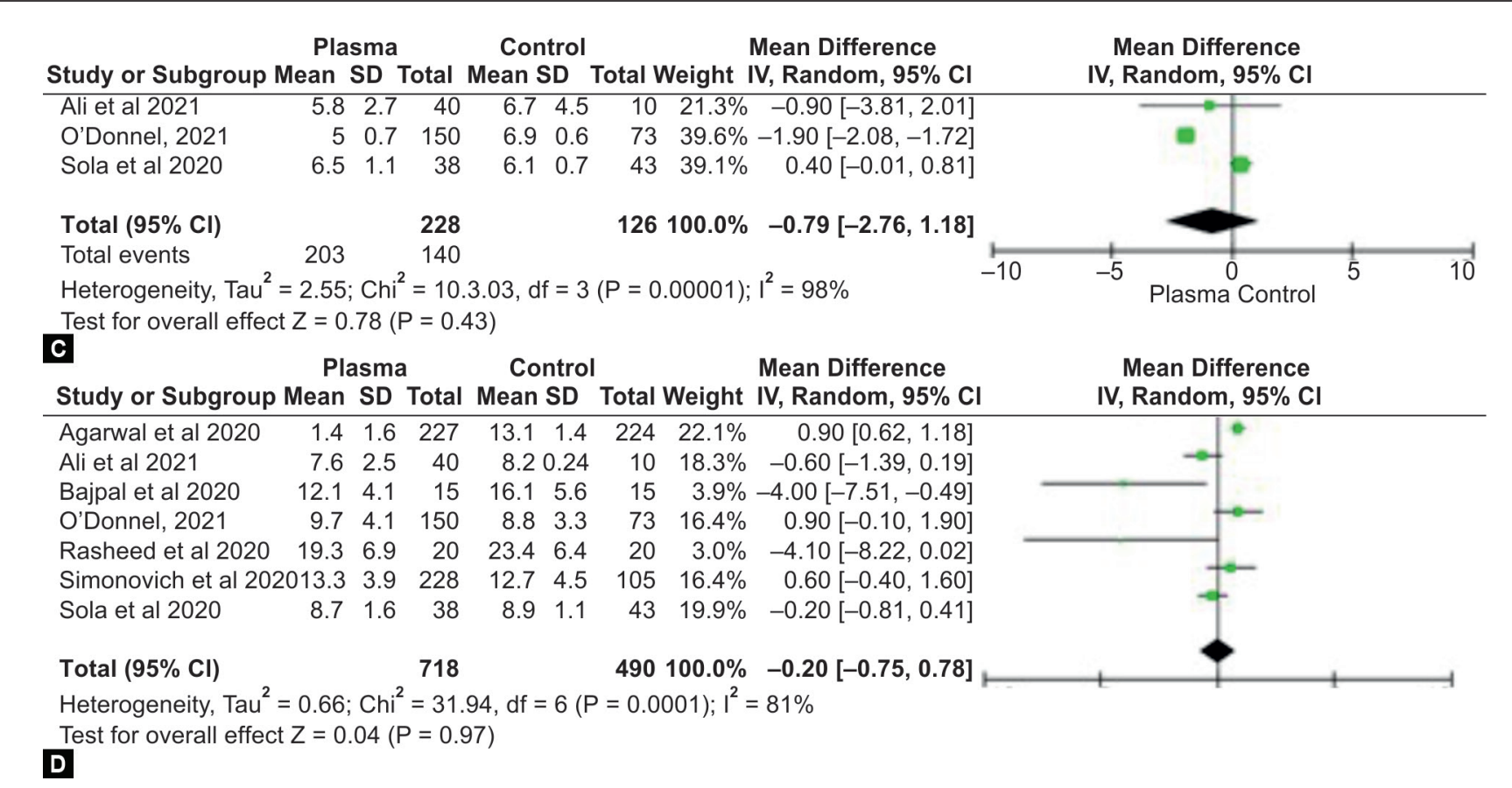

Figs 2C and D: (C) The impact of convalescent plasma therapy on duration for clinical improvement in COVID-19 patients; (D) The impact of convalescent plasma therapy on the period of hospital stays in COVID-19 patients

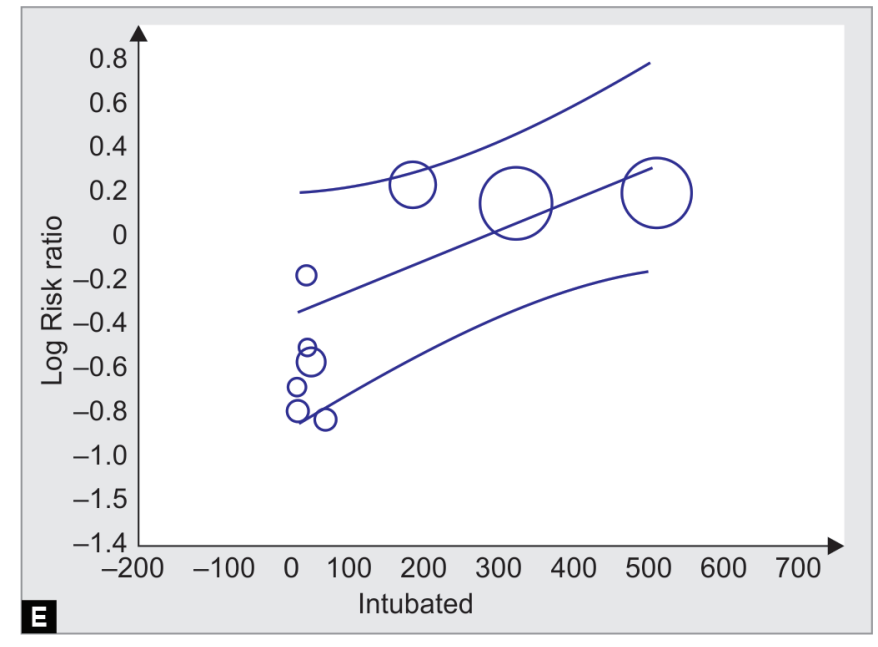

Fig. 2E: Meta-regression analysis showed that the association between convalescent plasma therapy and mortality was influenced by intubation status

$\mathrm{Cl}-3.82-0.58)$, and viral clearance on day 3 (RR $1.07,95 \% \mathrm{Cl} 0.58-1.8)$ and day 7 (RR 1.32, 95\% Cl 0.97-1.81). ${ }^{13}$

A recent systematic review and meta-analysis on severe acute respiratory infections of viral etiology reported that though the observational studies indicate a decline in mortality with CPT (OR $0.36,95 \% \mathrm{Cl} 0.23-0.56, p<0.00001$ ), the RCTs have not found any significant benefit for reducing the mortality (OR $0.82 ; 95 \% \mathrm{Cl}$ $0.57-1.19 ; p=0.30) .^{14}$

Rajendran et al. ${ }^{15}$ also could not provide any opinion regarding the efficacy of CPT in COVID-19 due to paucity in quantitative synthesis for their systemic review. Similarly, another recent metaanalysis of 10 RCTs also reported that in comparison with standard care, CPT did not reduce the all-cause mortality (RR: $1.02 ; 95 \% \mathrm{Cl}$ $0.92-1.12)^{16}$

We found an earlier administration of CPT is associated with better odds for favorable outcomes. Similarly, a number of recent studies ${ }^{17,18}$ also echoed that while early application of CPT is beneficial in critically ill COVID-19 patients, late CPT is futile. However, another recent RCT reported no significant reduction of mortality rate (OR $3.04,95 \% \mathrm{Cl} 0.54-17.2, p=0.25)$, and the requirement for mechanical ventilation (OR $3.04,95 \% \mathrm{Cl}$ $0.54-17.2, p=0.25$ ) is associated with early administration of CPT in comparison with the deferred patients. But it has to be noted that only $43.3 \%$ of the patients of the deferred group received CPT. ${ }^{19}$

A decline in per capita CPT, since late 2020 following the publication of several negative RCTs and meta-analyses resulted in approximately 29,000-36,000 excess deaths in the USA. Apart from the reaffirmation of the FDA for the Emergency Use Authorization for early CP with the adequate amount of antibodies in hospitalized patients again in February 2021, the guidelines of American Association of Blood Banks and Brazil also emphasized the early use of CP with high content of specific antibody. ${ }^{20}$

\section{Strengths and Limitations}

Our study is a comprehensive review using only RCTs for assessing the efficacy of CPT in COVID-19 patients using data from the COVID-19 studies and may be considered at the moment as the prime evidence for decision-making.

Although in the present scenario, the efficacy of CPT in COVID-19 patients is debatable; this meta-analysis provides a signal of benefit in COVID-19 patients. However, the findings are heterogeneous and of low-quality evidence. A significant variation regarding methodology, the timing of initiation, optimal dosage, and neutralizing antibody titer, and concomitant therapy have been noted across the studies. 


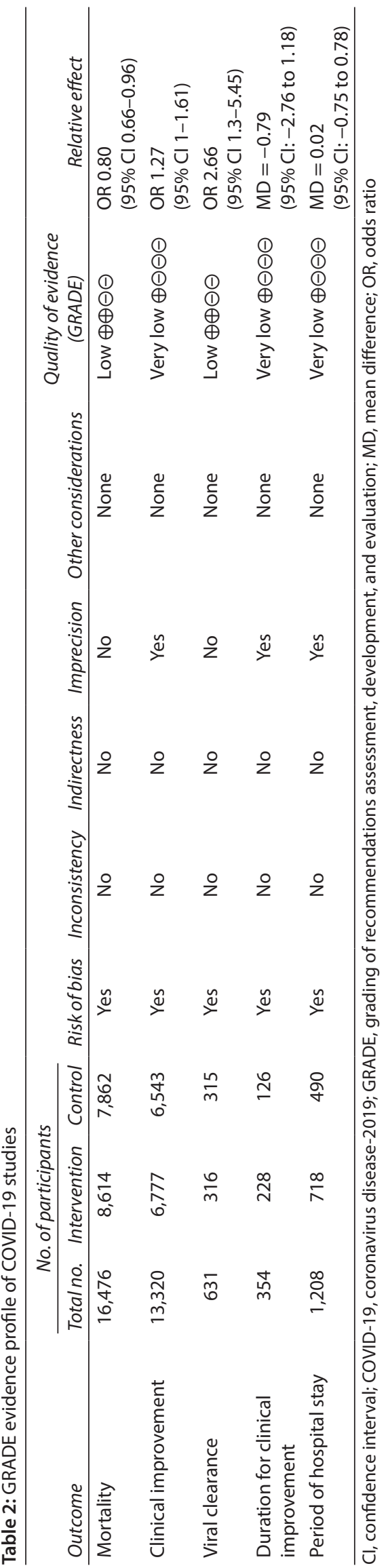

\section{Conclusion}

In conclusion, as the COVID-19 pandemic progresses, there is a desperate need for definitive treatment. Till the development of an effective treatment or vaccine, CPT seems to be a safe and effective option and the current evidence regarding the use of CPT in COVID-19 patients is encouraging. It is too early to write it off as a potential therapeutic modality for COVID-19 patients.

\section{ORCID}

Soumya Sarkar (1) https://orcid.org/0000-0003-0497-9909

Puneet Khanna 이 https://orcid.org/0000-0002-9243-9963

Akhil K Singh (1) https://orcid.org/0000-0002-6662-9819

\section{References}

1. Investigational COVID-19 Convalescent Plasma - Emergency INDs [Internet]. U.S. Food and Drug Administration; 2020. Available from: https://www.fda.gov/vaccines-blood-biologics/investigational-newdrug-ind-or-device-exemption-ide-process-cber/recommendationsinvestigational-covid-19-convalescent-plasma.

2. Casadevall A, Pirofski LA. The convalescent sera option for containing COVID-19. J Clin Invest 2020;130(4):1545-1548. DOI: $10.1172 / \mathrm{JCl} 138003$.

3. Use of convalescent whole blood or plasma collected from patients recovered from Ebola virus disease for transfusion, as an empirical treatment during outbreaks. Geneva: World Health Organization; 2014. Available from: www.who.int/csr/resources/publications/ebola/ convalescent-treatment/en [accessed February 16, 2021].

4. Marano G, Vaglio S, Pupella S, Facco G, Catalano L, Liumbruno GM, et al. Convalescent plasma: new evidence for an old therapeutic tool? Blood Transfus 2016;14(2):152-157. DOI: 10.2450/2015.0131-15.

5. Luke TC, Kilbane EM, Jackson JL, Hoffman SL. Meta-analysis: convalescent blood products for Spanish influenza pneumonia: a future H5N1 treatment? Ann Intern Med 2006;145(8):599-609. DOI: 10.7326/0003-4819-145-8-200610170-00139.

6. Soo YO, Cheng Y, Wong R, Hui DS, Lee CK, Tsang KK, et al. Retrospective comparison of convalescent plasma with continuing high-dose methylprednisolone treatment in SARS patients. Clin Microbiol Infect 2004;10(7):676-678. DOI: 10.1111/j.1469-0691.2004.00956.x.

7. Hung IF, To KK, Lee CK, Lee KL, Chan K, Yan WW, et al. Convalescent plasma treatment reduced mortality in patients with severe pandemic influenza A (H1N1) 2009 virus infection. Clin Infect Dis 2011;52(4):447-456. DOI: 10.1093/cid/ciq106.

8. Zhou B, Zhong N, Guan Y. Treatment with convalescent plasma for influenza A (H5N1) infection. N Engl J Med 2007;357(14):1450. DOI: 10.1056/NEJMc070359.

9. Mair-Jenkins J, Saavedra-Campos M, Baillie JK, Cleary P, Khaw FM, Lim WS, et al. The effectiveness of convalescent plasma and hyperimmune immunoglobulin for the treatment of severe acute respiratory infections of viral etiology: a systematic review and exploratory meta-analysis. J Infect Dis 2015;211(1):80-90. DOI: 10.1093/infdis/jiu396.

10. Sarkar S, Soni KD, Khanna P. Convalescent plasma is a clutch at straws in COVID-19 management! A systematic review and meta-analysis. J Med Virol 2020:10.1002/jmv.26408. DOI: 10.1002/jmv.26408. PMID: 32776573; PMCID: PMC7436491.

11. Khadka S, Saleem M, Shrestha D, Budhathoki P. Safety and efficacy of convalescent plasma therapy for the management of COVID-19: a systematic review. Aging 2020;13(1):1498-1509. DOI: 10.18632/ aging.202195.

12. Piechotta V, Chai KL, Valk SJ, Doree C, Monsef I, Wood EM, et al. Convalescent plasma or hyperimmune immunoglobulin for people with COVID-19: a living systematic review. Cochrane Database Syst Rev 2020;7(7):CD013600. DOI: 10.1002/14651858.CD013600.pub2. PMID: 32648959; PMCID: PMC7389743. 
13. Devasenapathy N, Ye Z, Loeb M, Fang F, Najafabadi BT, Xiao Y, et al. Efficacy and safety of convalescent plasma for severe COVID-19 based on evidence in other severe respiratory viral infections: a systematic review and meta-analysis. CMAJ 2020;192(27):E745. DOI: 10.1503/ cmaj.200642.

14. Shao S, Wang $Y$, Kang $H$, Tong Z. Effect of convalescent blood products for patients with severe acute respiratory infections of viral etiology: a systematic review and meta-analysis. Int J Infect Dis 2020:S1201-9712(20)32159-7. DOI: 10.1016/j.ijid.2020.09.1443. PMID: 33002611.

15. Rajendran K, Krishnasamy N, Rangarajan J, Rathinam J, Natarajan M, Ramachandran A. Convalescent plasma transfusion for the treatment of COVID-19: Systematic review. J Med Virol 2020;92(9):1475-1483. DOI: 10.1002/jmv.25961.

16. Janiaud $P$, Axfors $C$, Schmitt AM, Gloy V, Ebrahimi F, Hepprich M, et al. Association of convalescent plasma treatment with clinical outcomes in patients with COVID-19: a systematic review and meta-analysis. JAMA 2021;325(12):1185-1195. DOI: 10.1001/jama.2021.2747.
17. Briggs N, Gormally MV, Li F, Browning SL, Treggiari MM, Morrison A et al. Early but not late convalescent plasma is associated with better survival in moderate-to-severe COVID-19. medRxiv 2021:2021.06.16.21258972. DOI: 10.1101/2021.06.16.21258972.

18. Fodor E, Müller V, Iványi Z, Berki T, Olga KP, Ambrus M, et al. Early transfusion of convalescent plasma improves the clinical outcome in severe SARS-CoV2 infection. medRxiv 2021:2021.05.25.21257770. DOI: 10.1101/2021.05.25.21257770.

19. Balcells ME, Rojas L, Le Corre N, Martínez-Valdebenito C, Ceballos ME, Ferrés $\mathrm{M}$, et al. Early versus deferred anti-SARS-CoV-2 convalescent plasma in patients admitted for COVID-19: a randomized phase II clinical trial. PLoS Med 2021;18(3):e1003415. DOI: 10.1371/journal. pmed.1003415.

20. Casadevall A, Dragotakes Q, Johnson PW, Senefeld JW, Klassen $\mathrm{SA}$, Wright RS, et al. Convalescent plasma use in the United States was inversely correlated with COVID-19 mortality: did plasma hesitancy cost lives? medRxiv 2021:2021.04.07.21255089. DOI: 10.1101/2021.04.07.21255089. 